\title{
Why, when and where did honey bee dance communication evolve?
}

\author{
Robbie l'Anson Price * and Christoph Grüter ${ }^{\dagger}$ \\ Department of Ecology and Evolution, University of Lausanne, Lausanne, Switzerland
}

Honey bees (Apis sp.) are the only known bee genus that uses nest-based communication to provide nest-mates with information about the location of resources, the so-called "dance language." Successful foragers perform waggle dances for high quality food sources and, when swarming, suitable nest-sites. However, since many species of social insects do not communicate the location of resources to their nest-mates, the question of why the "dance language" evolved in honey bees is of ongoing interest. We review recent theoretical and empirical research into the ecological circumstances that make dance communication beneficial in present day environments.

OPEN ACCESS

Edited by:

Margaret Jane Couvillon, University of Sussex, UK

Reviewed by: Douglas Benjamin Sponsler, The Ohio State University, USA Morgan Kathryn Carr-Markell, University of Minnesota, USA

${ }^{*}$ Correspondence:

Robbie l'Anson Price r.iansonprice@gmail.com

${ }^{\dagger}$ Present Address: Christoph Grüter, Institute of Zoology, Johannes

Gutenberg University Mainz, Johannes von Müller Weg 6, 55099 Mainz, Germany

Specialty section:

This article was submitted to Behavioral and Evolutionary Ecology,

a section of the journal

Frontiers in Ecology and Evolution

Received: 16 June 2015

Accepted: 19 October 2015

Published: 05 November 2015

Citation:

I'Anson Price R and Grüter C (2015) Why, when and where did honey bee dance communication evolve?

Front. Ecol. Evol. 3:125. doi: 10.3389/fevo.2015.00125
This research suggests that the "dance language" is most beneficial when food sources differ greatly in quality and are hard to find. The dances of extant honey bee species differ in important ways, and phylogenetic studies suggest an increase in dance complexity over time: species with the least complex dance were the first to appear and species with the most complex dance are the most derived. We review the fossil record of honey bees and speculate about the time and context (foraging vs. swarming) in which spatially referential dance communication might have evolved. We conclude that there are few certainties about when the "dance language" first appeared; dance communication could be older than 40 million years and, thus, predate the genus Apis, or it could be as recent as 20 million years when extant honey bee species diverged during the early Miocene. The most parsimonious scenario assumes it evolved in a sub-tropical to temperate climate with patchy vegetation, somewhere in Eurasia.

Keywords: honey bee, waggle dance evolution, dance language, evolution of communication, honey bee foraging, honey bee evolution, social insect communication

\section{INTRODUCTION}

In 1973, the Austrian scientist Karl von Frisch was awarded the Nobel Prize for his research on the honey bee waggle dance (Von Frisch, 1967). He recognized how this unique form of communication allowed bees to share information on the location of food sources with nest-mates. Von Frisch described the dance as "the most astounding example of non-primate communication that we know" (Von Frisch, 1967). However, there are still considerable gaps in our understanding of the ecological significance and evolutionary history of the honey bee "dance language" (Grüter and Farina, 2009). The dance, performed by a honey bee upon returning to the colony having successfully located a food source, offers information on the presence, odor, quality, direction, and distance of said food source, enabling nest-mates to exploit it (Von Frisch, 1967; Farina et al., 2005; Riley et al., 2005; Grüter and Farina, 2009). The direction information is conveyed through the orientation of the waggle run, whereas the distance information is expressed through the duration 
of the waggle run (for details see Von Frisch, 1967; Riley et al., 2005; Preece and Beekman, 2014). This direction and distance communication (also called "dance language") is unique to honey bees and will be the focus of this review. We aim to bring together research on how the honey bee and this complex form of communication evolved. We will do this by looking at theoretical and empirical studies on living honey bee species, and also phylogenetic and fossil studies on extinct and extant species. In bringing these studies together we hope to offer scenarios about where, when and why the dance language evolved.

\section{ECOLOGICAL CONTEXT: WHEN IS DANCE COMMUNICATION BENEFICIAL?}

An important feature of dance communication is that bees dance more for better resources (Von Frisch, 1967). A resource is graded depending on its energetic value with reference to the colonies current needs (Seeley, 1986, 1989). As a consequence, recruits of waggle dances can discover high quality food sources without having to sample other options in the area first-hand. There are, however, costs when using social information that do not exist when using other foraging strategies (memory or searching for new food sources) (Giraldeau et al., 2002; Grüter and Leadbeater, 2014). Recruited individuals often fail to find the advertised food source and must return to the colony to receive more information (Seeley and Visscher, 1988; Couvillon et al., 2014; Grüter and Leadbeater, 2014). Such failures are both temporally and energetically expensive. Furthermore, in rapidly changing environments social information can quickly become outdated and therefore unreliable (Giraldeau et al., 2002; Grüter and Leadbeater, 2014). Hence, there might be conditions when using spatial information within a waggle dance is not the most effective strategy. There are many examples of social insect species that do not communicate spatial information to nest mates, making the use of such communication in honey bees all the more interesting (Dornhaus and Chittka, 1999; Nieh, 2004).

The results of empirical and theoretical studies using Apis mellifera as a model system suggest that the benefits of spatial dance information depend critically on the spatiotemporal distribution of food sources (Sherman and Visscher, 2002; Dornhaus and Chittka, 2004; Beekman and Lew, 2008; Bailis et al., 2010; Donaldson-Matasci and Dornhaus, 2012; Schürch and Grüter, 2014). In particular, studies using horizontally oriented dance floors in the dark have provided interesting indications about the habitats in which the waggle dance is beneficial. By orienting the dance floor so the bees have no reference to gravity, the dance is disrupted and the spatial information (distance and direction, but not presence and olfactory information) is lost (Von Frisch, 1967). Consequently, bees still perform and follow dances but no useful spatial information is passed on. In a pioneering study, Sherman and Visscher (2002) looked at the effect of spatial information in the dance on foraging success during different periods of the year in California. They found that the spatial information improved foraging success in the winter, but not in the summer or autumn months. During winter, resources are sparser than in summer and using spatial information could be more beneficial during this period since the chances of discovering resources by independent scouting are lower. Similarly, a study carried out by Dornhaus and Chittka (2004) found spatial information to be beneficial to colony foraging success in a tropical habitat but not in two temperate habitats (Dornhaus and Chittka, 2004). Again the spatiotemporal distribution of resources was considered to be the reason for the result as tropical habitats are characterized by clustered and shorter-lived food sources when compared to temperate habitats. Donaldson-Matasci and Dornhaus (2012) assessed the benefits of spatial information in five habitats and found a positive effect in just one, a habitat characterized by many flower species. High species richness might increase the variability of floral rewards in the environment and spatial dance information could allow the colony to concentrate foraging on the most rewarding resources (Donaldson-Matasci and Dornhaus, 2014). Taken together, these empirical studies suggest that the benefits of the "dance language" are highly dependent on patterns of resource availability.

It is important to mention that the failure to detect foraging benefits of spatial information in certain habitats could be caused by methodological problems. First, sample sizes were small in these studies (2-6 colonies per location). Second, it has been argued that experimental designs were prone to being confounded by memory effects (Schürch and Grüter, 2014). Colonies were switched between normal and disrupted dance conditions every 2-3 days (Dornhaus and Chittka, 2004; Donaldson-Matasci and Dornhaus, 2012) or a variable number of days (Sherman and Visscher, 2002). Given that bees can return to the same resource location for many days (Ribbands, 1949; Moore and Doherty, 2009; Grüter and Ratnieks, 2011; Al Toufailia et al., 2013), it is not possible to determine whether the food sources exploited during one treatment were discovered during the same or a previous treatment period. In other words, a bee exploiting a food source during disoriented conditions might have been recruited to this food source days earlier by following an oriented dance. Schürch and Grüter (2014) used an agent based model to investigate this effect of memory by simulating various experimental designs (Schürch and Grüter, 2014). Their simulations suggest that the use of individual memory could have masked the benefits of spatial information in many environments.

Despite the aforementioned caveats, theoretical modeling studies strongly support the hypothesis that the benefit of spatial information depends on the spatiotemporal distribution of resources. Dornhaus et al. (2006) found that dancing should be most beneficial in environments where patches are few and of variable quality (Dornhaus et al., 2006), whereas Beekman and Lew found that dancing should be advantageous if patch sizes are small and therefore difficult to find (Beekman and Lew, 2008). Schürch and Grüter (2014) similarly found dance recruitment to a resource to be most beneficial when food sites are at low densities, but their simulations also revealed a more unexpected finding. It is usually thought that dancing is most beneficial when resource patches are ephemeral (Sherman and Visscher, 2002; 
Grüter and Ratnieks, 2011), but Schürch and Grüter's results suggested spatial information helps most when food sources are stable for longer periods of time because successful recruitment events lead to long-term benefits through individual memory (Schürch and Grüter, 2014).

Given these empirical and theoretical findings it has been suggested that the "dance language" evolved in a tropical habitat in response to the clustered spatial distribution of food patches and the great diversity of food sources (Sherman and Visscher, 2002; Dornhaus and Chittka, 2004; Dornhaus et al., 2006). However, it is important to note that details of dance communication, e.g., the precision of dancing or the ability of dance followers to extract information and locate advertised food sources, would most likely have been different when it first evolved. These aspects affect the costs and benefits of dancing and, therefore, the colony-level performance gains for dancing ancestors might have been different.

\section{EVOLUTIONARY CONTEXT: WHERE AND WHEN DID THE "DANCE LANGUAGE" EVOLVE?}

\section{Extant Species of Apis}

The greatest diversity of extant Apis species is found in tropical Asia. There is debate as to the true number of Apis species: at the conservative end there are 6 or 7 (Alexander, 1991; Engel and Schultz, 1997) recognized extant species of Apis, while others have argued that there are 10 or 11 species (Arias and Sheppard, 2005; Lo et al., 2010). All extant species dance to communicate the location of food resources and nest sites (Dyer, 2002; Oldroyd and Wongsiri, 2006; Beekman et al., 2015). There is a general consensus between morphological, molecular and behavior studies as to the evolution of the honey bees (Engel and Schultz, 1997). The dwarf honey bees (extant species A. florea and A. andreniformis) were the first to diverge from an Apis ancestor (Kotthoff et al., 2013). Dwarf honey bees are open-nesting species that construct a single wax comb on a tree branch (Alexander, 1991; Wongsiri et al., 1996; Michener, 2000; Arias and Sheppard, 2005). The next species to diverge were the open-nesting giant honey bees (extant species $A$. dorsata and A. laboriosa). Giant honey bees construct a single wax comb under tree branches, rocks and also human buildings. The most derived species are the cavity nesting honey bees (extant species A. mellifera, A. cerana, A. nigrocincta, and A. koschevnikovi).

All extant species dance to communicate the location of food resources and nest sites (Dyer, 2002; Oldroyd and Wongsiri, 2006; Beekman et al., 2015). Pioneering research by Martin Lindauer on three of these species led to his proposal that there is a progression in dance complexity that corresponds to phylogenetic development of the dance (Lindauer, 1956). A. florea (dwarf honey bee) uses celestial cues when orienting its dance and is unable to use gravity as a reference (Lindauer, 1956). This honey bee indicates food source location by dancing on a horizontal or sloped (Dyer, 2002) surface in the direction of the food source (Figure 1A) (Koeniger et al., 1982). Apis dorsata, (giant honey bee) dances on the vertical comb surface

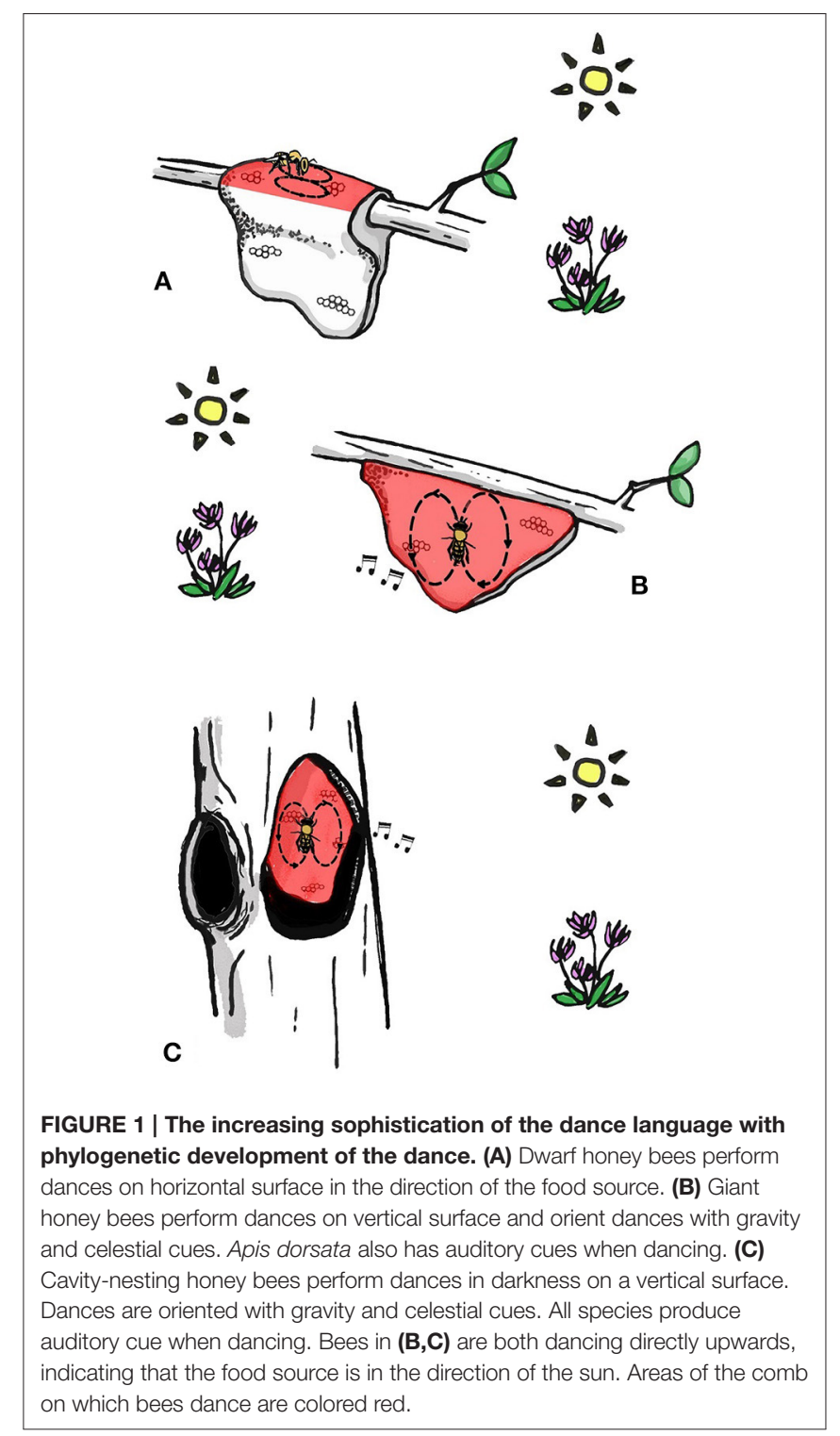

and therefore cannot point in the direction of the food source (Dyer, 1985), but instead translates the direction to the food source in relation to the position of the sun into a waggle run angle relative to gravity (Figure 1B) (Dyer, 2002, Figure 1.2). Interestingly, $A$. dorsata can use gravity without direct sight of the sun (Dyer, 1985), for example when foraging nocturnally (using the suns position despite it being beyond the horizon) or under a blanket of other bees (Dyer, 1985; Oldroyd and Wongsiri, 2006). Apis dorsata also produce auditory signals when dancing, which might assist followers in finding and following dances performed in the dark (Michelsen et al., 1986; Kirchner and Dreller, 1993). Finally, the most derived form of the waggle dance is carried out by cavity dwelling A. cerana, A. mellifera, A. nuluensis, and A. nigrocinta. Cavity dwelling species are able to use celestial cues on a horizontal dance floor when swarming or on experimentally manipulated combs (only studied in A. cerana and $A$. mellifera), but most of the time they orientate their dances 
with reference to gravity in the dark nest (Figure 1C). These species also produce auditory signals when dancing (Michelsen et al., 1986). The ability to orientate dances in complete darkness might have enabled bees to nest in cavities, because prior to this they could not communicate in the dark. However, it is possible that cavity-nesting evolved before the ability to orient dances in darkness using gravity (Oldroyd and Wongsiri, 2006). The dances of A. mellifera and A. cerana are so similar that each species will follow and decode dances of the other (Tan et al., 2008).

A study carried out by Raffiudin and Crozier supports several aspects of Lindauer's hypothesis of an evolutionary sequence from open nesting with less complex dances to cavity nesting with more complex dances (Raffiudin and Crozier, 2007). Based on DNA sequences of several honey bee species they found that the common ancestor of extant honey bees probably nested in the open and likely to have produced silent dances on a single vertical comb (Engel and Schultz, 1997). Raffiudin and Crozier (2007) suggest that the common ancestor of Apis danced vertically, not horizontally like the dwarf honey bees (but see Engel and Schultz, 1997). The common ancestor of the giant and cavity-nesting honey bees was inferred to have had a sound-producing vertical dance (Oldroyd and Wongsiri, 2006) suggesting that sound production when dancing evolved once. Interestingly, the giant honey bee A. laboriosa does not seem to produce sounds and it remains unknown whether this acoustical addition was lost in A. laboriosa or if it were gained independently in giant and cavity-nesting honey bees (Kirchner et al., 1996).

\section{Extinct Ancestors}

Bees evolved from apoid wasps (Apoidea) approximately 140110 million years ago (Danforth et al., 2013). The oldest known eusocial bee fossil is Cretotrigona prisca. It was found in Cretaceous New Jersey amber and is estimated to be 65-70 million years old (Michener and Grimaldi, 1988; Engel, 2000). This fossil is remarkable because of its similarities with workers of present day stingless bees (Meliponini), which are a derived group of highly eusocial bees. The fossil indicates that sociality most likely existed in bees during this period and this is a key prerequisite for the evolution of dance communication. The weak fossil record of bees older than 50 million years means that it is difficult to put an accurate date on the origin of the genus Apis. Many fossilized Hymenoptera have been found in Baltic amber (40-50 million years old) (Ruttner, 1988). During this period global temperature started to decrease (Zachos et al., 2001) and Europe became more temperate. Such changes would have affected resource distribution and therefore may have affected the costs and benefits of foraging communication.

It was long believed that Apis evolved and diversified in tropical Asia (e.g., Ruttner, 1988), but Apis fossils discovered in France and Germany in recent years, in combination with the current distribution of honey bee species, suggest that the center of origin was in Europe, most likely around the time of the major climatic shift of the Eocene-Oligocene transition (c. 30 million years ago, see Figure 2) (Engel, 2006; Kotthoff et al., 2013). These fossils show a remarkable morphological diversity in European

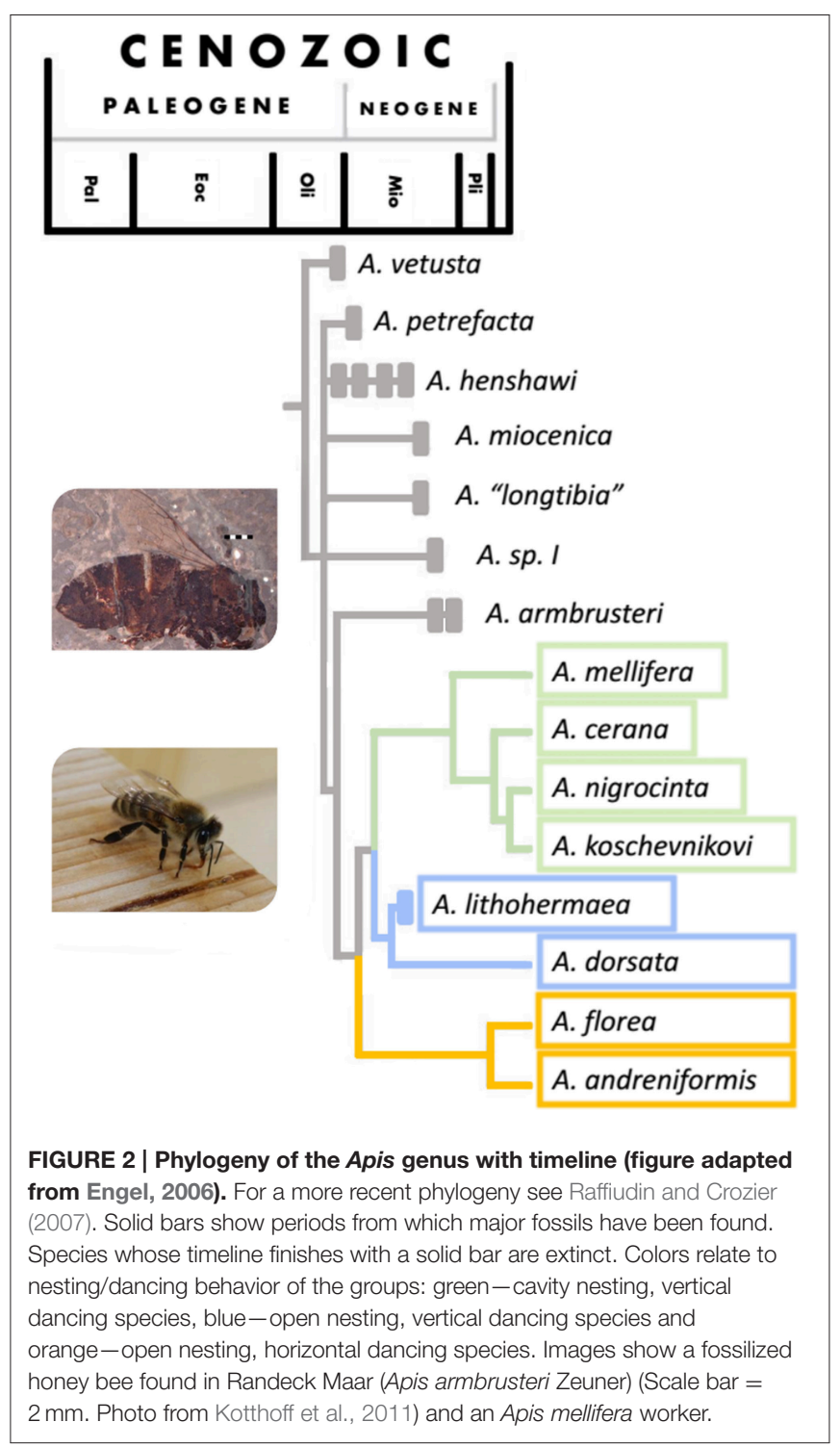

Apini during the late Oligocene and early Miocene (Kotthoff et al., 2011). If the dance did originate at the same time as Apis then it might have evolved in Europe, rather than in Asia. Fossils from Japan and the US suggest that different species of honey bee were present in many areas of the world during the Miocene (Nel et al., 1999; Engel, 2006; Engel et al., 2009; Kotthoff et al., 2011, 2013), but a global cooling starting in Mid-Miocene (c. 15 million years ago) probably brought the demise of ancient honey bees in Europe, some parts of Asia and Northern America (Ruttner, 1988; Engel et al., 2009).

We can see evidence of advanced eusociality in Apis fossils (worker-like morphology), though it is highly likely that it evolved well before the first Apis appeared [both Cretotrigona prisca (65-70 million years old) and Electrapis (33.9-56 million years old) are considered highly eusocial (Engel, 1998; Grimaldi and Engel, 2005)]. Fossilized A. armbrusteri (see Figure 2), a honeybee that lived around 25-20 million years ago in Europe resemble the workers of $A$. mellifera and one particular $A$. 
armbrusteri fossil contains 17 closely packed individuals; possibly a fragment of a swarm (Seeley, 1985).

\section{When and in What Context Did Waggle Dance Communication Evolve?}

Some authors have proposed that the honey bee dance originally evolved to allow bees to select a nest site and that the dance was only later co-opted for foraging (Oldroyd and Wongsiri, 2006; Beekman et al., 2008; Beekman and Lew, 2008). Indeed, dance communication plays a fundamental role during swarming and nest-site selection (Seeley, 2010): when colonies look for a new nest site they send out scouts to evaluate and propose different options to their sisters with their dances. This leads to the build-up of more scouts at good nest sites until a quorum is reached at a particularly good site. Then the swarm lifts off and flies to this new nest location (Seeley, 2010). Thus, it is hard to see how honey bee swarming would work without dance communication. Of course if swarming functioned in a different way in ancestral honey bees then the "dance language" may not have been required. As we have seen earlier, the "dance language" does not seem to be equally important in foraging. There are other species of social insects that communicate the location of nest sites, but not of food sources. Many swarmfounding wasps, for example, use pheromone trails to recruit nest-mates to new nest-sites, but not to food sources (Jeanne, 1980). On the other hand, early Apis were probably opennesting species and therefore nest sites (branches on a tree) would have been relatively easy find in the vicinity of the mother nest. Food sites, however, were subject to competition and the dance would enable a colony to locate and exploit them even if they were at a substantial distance from the nest (Ratnieks and Shackleton, 2015). The dance may then have been co-opted for nest site location as bees diversified and became more specialized. A third possibility is that it evolved simultaneously in both contexts. If high quality nest sites and high quality food sources both represent rewards for bees and are processed in similar ways in the bee brain, then dance communication might have been used in both contexts as soon as it appeared. Work on the neurological basis of reward learning in bees has shown that there are particular neurons within the bee brain that encode and process reward information (Hammer, 1997). It would be interesting to know if the same neurons are involved when evaluating new nest sites.

Dance communication probably evolved in a highly eusocial species. However, because the phylogenetic relationships among the corbiculate bees are still not resolved (reviewed in Almeida and Porto, 2014) it remains unclear when honey bee ancestors evolved higher eusociality. If it evolved twice, once in the Meliponini and once in the Apini (Cameron, 1993; Koulianos et al., 1999; Cameron and Mardulyn, 2001; Cardinal and Danforth, 2011), then higher eusociality evolved after the two groups separated c. 80 million years ago (Cardinal and Danforth, 2011). If, however, Apini and Meliponini are sister groups with a common highly eusocial ancestor (Roig-Alsina et al., 1993; Engel, 2001; Noll, 2002; Cardinal and Packer, 2007), then higher eusociality in Apis ancestors is probably older than 80 million years. Thus, there is a possibility that spatially referential dancelike communication evolved as early as c. 70-80 million years ago. However, this seems very unlikely and the "dance language" is probably much younger. Extant honey bees diverged in the early Miocene (ca. 20 million years ago) (Engel, 2006; Cardinal and Danforth, 2011). Because all extant species use the "dance language" we can be confident that their common ancestor also used a dance communication (Oldroyd and Wongsiri, 2006; Raffiudin and Crozier, 2007). This provides a lower boundary of c. 20 million years before present for the evolution of the "dance language." Genetic analyses suggest the split between the cavity nesting A. mellifera and A. cerana may have occurred 8 million years ago (Han et al., 2012), which would imply that the dances in dark cavities are at least 8 million years old.

Seeley (1985) suggested that a period of honey bee diversification around the Eocene/Oligocene boundary was followed by a period of 30 million years of relative stasis in their morphological evolution. He argued that if social behavior and worker morphology evolved in tandem, the social organization and communication system (including the waggle dance) we see today in honey bees would be at least 30 million years old (Seeley, 1985). On the other hand, fossils discovered in recent years show a great amount of morphological diversity in European Apini during the Miocene (23-5.3 million years ago) (Kotthoff et al., 2011, 2013). In our opinion, it is currently not possible to exclude a much earlier or a later origin of the "dance language."

\section{CONCLUSIONS}

A combination of theoretical and empirical studies has increased our understanding of why present day honey bees dance to indicate the location of valuable resources. These studies suggest that the spatial information acquired from a dance is most valuable in environments with resources that are spatially clustered, difficult to find, temporally stable, and variable in quality. Phylogenetic studies offer support for the theory of progressing dance complexity with phylogenetic development. The fossil record of Apis has become more informative in recent years and this information suggests that the genus originated in Europe rather than in Asia. This raises the possibility that the "dance language" evolved in Europe as well. We cannot exclude that the "dance language" pre-dates the earliest Apis, but it is likely to be younger and could have evolved as recently as 20 million years ago when the extant honey bee species diverged during the early Miocene.

Future empirical work should further explore the costs and benefits of dance communication. The work of Seeley (1983) and Seeley and Visscher (1988) suggests that dance following in A. mellifera living in temperate habitats is more costly in terms of time than independent food search, but leads to better food sources. However, what about costs and benefits in other habitats and in other species? Furthermore, if the waggle dance is of less benefit to the colony in temperate climates, do bees in temperate areas use the language more selectively? 


\section{ACKNOWLEDGMENTS}

We thank Michael Engel for providing information about the evolution of Apis, Chloé Schmidt for the drawings in

\section{REFERENCES}

Alexander, B. A. (1991). Phylogenetic analysis of the genus Apis (Hymenoptera: Apidae). Ann. Entomol. Soc. Am. 84, 137-149. doi: 10.1093/aesa/84.2.137

Almeida, E. A., and Porto, D. S. (2014). Investigating eusociality in bees while trusting the uncertainty. Sociobiology 61, 355-368. doi: 10.13102/sociobiology.v61i4.355-368

Al Toufailia, H. M., Grüter, C., and Ratnieks, F. L. W. (2013). Persistence to unrewarding feeding locations by honeybee foragers (Apis mellifera): the effects of experience, resource profitability and season. Ethology 119, 1096-1106. doi: 10.1111/eth. 12170

Arias, M. C., and Sheppard, W. S. (2005). Phylogenetic relationships of honey bees (Hymenoptera: Apinae: Apini) inferred from nuclear and mitochondrial DNA sequence data. Mol. Phylogenet. Evol. 37, 25-35. doi: 10.1016/j.ympev.2005.02.017

Bailis, P., Nagpal, R., and Werfel, J. (2010). Positional communication and private information in honeybee foraging models. Lect. Notes Comput. Sci. 6234, 263-274. doi: 10.1007/978-3-642-15461-4_23

Beekman, M., Gloag, R. S., Even, N., Wattanachaiyingchareon, W., and Oldroyd, B. P. (2008). Dance precision of Apis florea - clues to the evolution of the honeybee dance language? Behav. Ecol. Sociobiol. 62, 1259-1265. doi: 10.1007/s00265008-0554-z

Beekman, M., and Lew, J. B. (2008). Foraging in honeybees - when does it pay to dance? Behav. Ecol. 19, 255-262. doi: 10.1093/beheco/arm117

Beekman, M., Makinson, J. C., Couvillon, M. J., Preece, K., and Schaerf, T. M. (2015). Honeybee linguistics-a comparative analysis of the waggle dance among species of Apis. Front. Ecol. Evol. 3:11. doi: 10.3389/fevo.2015.00011

Cameron, S. A. (1993). Multiple origins of advanced eusociality in bees inferred from mitochondrial DNA sequences. Proc. Natl. Acad. Sci. U.S.A. 90, 86878691. doi: $10.1073 /$ pnas.90.18.8687

Cameron, S. A., and Mardulyn, P. (2001). Multiple molecular data sets suggest independent origins of highly eusocial behavior in bees (Hymenoptera: Apinae). Syst. Biol. 50, 194-214. doi: 10.1080/10635150151125851

Cardinal, S., and Danforth, B. N. (2011). The antiquity and evolutionary history of social behavior in bees. PLoS ONE 6:e21086. doi: 10.1371/journal.pone.0021086

Cardinal, S., and Packer, L. (2007). Phylogenetic analysis of the corbiculate Apinae based on morphology of the sting apparatus (Hymenoptera: Apidae). Cladistics 23, 99-118. doi: 10.1111/j.1096-0031.2006.00137.x

Couvillon, M. J., Fensome, K. A., Quah, S. K., and Schürch, R. (2014). Summertime blues: august foraging leaves honey bees empty-handed. Commun. Integr. Biol. 7, e93495. doi: 10.4161/cib.28821

Danforth, B. N., Cardinal, S., Praz, C., Almeida, E. A. B., and Michez, D. (2013). The impact of molecular data on our understanding of bee phylogeny and evolution. Annu. Rev. Entomol. 58, 57-78. doi: 10.1146/annurev-ento-120811153633

Donaldson-Matasci, M. C., and Dornhaus, A. (2012). How habitat affects the benefits of communication in collectively foraging honey bees. Behav. Ecol. Sociobiol. 66, 583-592. doi: 10.1007/s00265-011-1306-z

Donaldson-Matasci, M., and Dornhaus, A. (2014). Dance communication affects consistency, but not breadth, of resource use in pollen-foraging honey bees. PLoS ONE 9:e107527. doi: 10.1371/journal.pone.0107527

Dornhaus, A., and Chittka, L. (1999). Evolutionary origins of bee dances. Nature 401, 38-38. doi: 10.1038/43372

Dornhaus, A., and Chittka, L. (2004). Why do honey bees dance? Behav. Ecol. Sociobiol. 55, 395-401. doi: 10.1007/s00265-003-0726-9

Dornhaus, A., Klügl, F., Oechslein, C., Puppe, F., and Chittka, L. (2006). Benefits of recruitment in honey bees: effects of ecology and colony size in an individualbased model. Behav. Ecol. 17, 336-344. doi: 10.1093/beheco/arj036

Dyer, F. C. (1985). Nocturnal orientation by the Asian honey bee, Apis dorsata. Anim. Behav. 33, 769-774. doi: 10.1016/S0003-3472(85)80009-9
Figure 1 and Eric Lucas for comments. We also thank two reviewers for their helpful suggestions. This work was funded by an Ambizione Fellowship from the Swiss NSF (PZOOP3_142628/1).

Dyer, F. C. (2002). The biology of the dance language. Annu. Rev. Entomol. 47, 917-949. doi: 10.1146/annurev.ento.47.091201.145306

Engel, M. (1998). A new species of the Baltic amber bee genus Electrapis (Hymenoptera: Apidae). J. Hymenopt. Res. 7, 94-101.

Engel, M. S. (2000). A new interpretation of the oldest fossil bee (Hymenoptera: Apidae). Am. Mus. Novit. 3296, 1-11. doi: 10.1206/0003-0082(2000)3296 $<0001$ :ANIOTO>2.0.CO;2

Engel, M. S. (2001). Monophyly and extensive extinction of advanced eusocial bees: insights from an unexpected Eocene diversity. Proc. Natl. Acad. Sci. U.S.A. 98, 1661-1664. doi: 10.1073/pnas.98.4.1661

Engel, M. S. (2006). A giant honey bee from the middle Miocene of Japan (Hymenoptera: Apidae). Am. Mus. Novit. 3504, 1-12. doi: 10.1206/00030082(2006)504[0001:AGHBFT]2.0.CO;2

Engel, M. S., Hinojosa-Díaz, I. A., and Rasnitsyn, A. P. (2009). A honey bee from the Miocene of Nevada and the biogeography of Apis (Hymenoptera: Apidae: Apini). Proc. Calif. Acad. Sci. 60, 23-38.

Engel, M. S., and Schultz, T. R. (1997). Phylogeny and behavior in honey bees (Hymenoptera: Apidae). Ann. Entomol. Soc. Am. 90, 43-53. doi: 10.1093/aesa/90.1.43

Farina, W. M., Grüter, C., and Díaz, P. C. (2005). Social learning of floral odours within the honeybee hive. Proc. R. Soc. Lond. B Biol. Sci. 272, 1923-1928. doi: $10.1098 /$ rspb.2005.3172

Giraldeau, L. A., Valone, T. J., and Templeton, J. J. (2002). Potential disadvantages of using socially acquired information. Philos. Trans. R. Soc. Lond. B Biol. Sci. 357, 1559-1566. doi: 10.1098/rstb.2002.1065

Grimaldi, D., and Engel, M. S. (2005). Evolution of the Insects. Cambridge: Cambridge University Press.

Grüter, C., and Farina, W. M. (2009). The honeybee waggle dance: can we follow the steps? Trends Ecol. Evol. 24, 242-247. doi: 10.1016/j.tree.2008.12.007

Grüter, C., and Leadbeater, E. (2014). Insights from insects about adaptive social information use. Trends Ecol. Evol. 29, 177-184. doi: 10.1016/j.tree.2014.01.004

Grüter, C., and Ratnieks, F. L. W. (2011). Honeybee foragers increase the use of waggle dance information when private information becomes unrewarding. Anim. Behav. 81, 949-954. doi: 10.1016/j.anbehav.2011.01.014

Hammer, M. (1997). The neural basis of associative reward learning in honeybees. Trends Neurosci. 20, 245-252. doi: 10.1016/S0166-2236(96)01019-3

Han, F., Wallberg, A., and Webster, M. (2012). From where did the Western honeybee (Apis mellifera) originate. Ecol. Evol. 2, 1949-1957. doi: 10.1002/ ece 3.312

Jeanne, R. L. (1980). Evolution of social behavior in the Vespidae. Annu. Rev. Entomol. 25, 371-396. doi: 10.1146/annurev.en.25.010180.002103

Kirchner, W., Dreller, C., Grasser, A., and Baidya, D. (1996). The silent dances of the Himalayan honeybee, Apis laboriosa. Apidologie 27, 331-339. doi: 10.1051/apido:19960501

Kirchner, W. H., and Dreller, C. (1993). Acoustical signals in the dance language of the giant honeybee, Apis dorsata. Behav. Ecol. Sociobiol. 33, 67-72. doi: 10.1007/BF00171657

Koeniger, N., Koeniger, G., Punchihewa, R., and Fabritius, M. (1982). Observations and experiments on dance communication in Apis florea in Sri Lanka. J. Apic. Res. 21, 45-52.

Kotthoff, U., Wappler, T., and Engel, M. S. (2011). Miocene honey bees from the Randeck Maar of southwestern Germany (Hymenoptera, Apidae). ZooKeys 96, 11-37. doi: 10.3897/zookeys.96.752

Kotthoff, U., Wappler, T., and Engel, M. S. (2013). Greater past disparity and diversity hints at ancient migrations of European honey bee lineages into Africa and Asia. J. Biogeogr. 40, 1832-1838. doi: 10.1111/jbi.12151

Koulianos, S., Schmid-Hempel, R., Roubik, D., and Schmid-Hempel, P. (1999). Phylogenetic relationships within the corbiculate Apinae (Hymenoptera) and the evolution of eusociality. J. Evol. Biol. 12, 380-384. doi: 10.1046/j.14209101.1999.00043.x 
Lindauer, M. (1956). Über die Verständigung bei indischen Bienen. Z. Vergleichende Physiol. 38, 521-557. doi: 10.1007/BF00341108

Lo, N., Gloag, R. S., Anderson, D. L., and Oldroyd, B. P. (2010). A molecular phylogeny of the genus Apis suggests that the Giant Honey Bee of the Philippines, A. breviligula Maa, and the Plains Honey Bee of southern India, A. indica Fabricius, are valid species. Syst. Entomol. 35, 226-233. doi: 10.1111/j.1365-3113.2009.00504.x

Michelsen, A., Kirchner, W. H., and Lindauer, M. (1986). Sound and vibrational signals in the dance language of the honeybee, Apis mellifera. Behav. Ecol. Sociobiol. 18, 207-212. doi: 10.1007/BF00290824

Michener, C. D. (2000). The Bees of the World. Baltimore, MD: JHU Press.

Michener, C. D., and Grimaldi, D. A. (1988). The oldest fossil bee: apoid history, evolutionary stasis, and antiquity of social behavior. Proc. Natl. Acad. Sci. U.S.A. 85, 6424-6426. doi: 10.1073/pnas.85.17.6424

Moore, D., and Doherty, P. (2009). Acquisition of a time-memory in forager honey bees. J. Comp. Physiol. A 195, 741-751. doi: 10.1007/s00359-009-0450-7

Nel, A., Martínez-Delclos, X., Arillo, A., and Penalver, E. (1999). A review of the Eurasian fossil species of the bee Apis. Palaeontology 42, 243-285. doi: $10.1111 / 1475-4983.00073$

Nieh, J. C. (2004). Recruitment communication in stingless bees (Hymenoptera, Apidae, Meliponini). Apidologie 35, 159-182. doi: 10.1051/apido:2004007

Noll, F. B. (2002). Behavioral phylogeny of corbiculate Apidae (Hymenoptera; Apinae), with special reference to social behavior. Cladistics 18, 137-153. doi: 10.1111/j.1096-0031.2002.tb00146.x

Oldroyd, B. P., and Wongsiri, S. (2006). Asian Honey Bees: Biology, Conservation, and Human Interactions. Cambridge, MA: Harvard University Press.

Preece, K., and Beekman, M. (2014). Honeybee waggle dance error: adaption or constraint? Unravelling the complex dance language of honeybees. Anim. Behav. 94, 19-26. doi: 10.1016/j.anbehav.2014. 05.016

Raffiudin, R., and Crozier, R. H. (2007). Phylogenetic analysis of honey bee behavioral evolution. Mol. Phylogenet. Evol. 43, 543-552. doi: 10.1016/j.ympev.2006.10.013

Ratnieks, F. L., and Shackleton, K. (2015). Does the waggle dance help honey bees to forage at greater distances than expected for their body size? Front. Ecol. Evol. 3:31. doi: $10.3389 /$ fevo. 2015.00031

Ribbands, C. R. (1949). The foraging method of individual honey-bees. J. Anim. Ecol. 18, 47-66. doi: 10.2307/1581

Riley, J. R., Greggers, U., Smith, A. D., Reynolds, D. R., and Menzel, R. (2005). The flight paths of honeybees recruited by the waggle dance. Nature 435, 205-207. doi: $10.1038 /$ nature 03526

Roig-Alsina, A., Michener, C. D., and Silveira, F. A. (1993). Studies of the phylogeny and classification of long-tongued bees (Hymenoptera: Apoidea). Univ. Kans. Sci. Bull. 55, 124-162.
Ruttner, F. (1988). Biogeography and Taxonomy of Honeybees. New York, NY: Springer-Verlag.

Schürch, R., and Grüter, C. (2014). Dancing bees improve colony foraging success as long-term benefits outweigh short-term costs. PLoS ONE 9:e104660. doi: 10.1371/journal.pone. 0104660

Seeley, T. D. (1983). Division of labor between scouts and recruits in honeybee foraging. Behav. Ecol. Sociobiol. 12, 253-259. doi: 10.1007/BF00290778

Seeley, T. D. (1985). Honeybee Ecology: a Study of Adaptation in Social Life. Princeton, NJ: Princeton University Press. doi: 10.1515/9781400857876

Seeley, T. D. (1986). Social foraging by honeybees - how colonies allocate foragers among patches of flowers. Behav. Ecol. Sociobiol. 19, 343-354. doi: 10.1007/BF00295707

Seeley, T. D. (1989). Social foraging in honey bees: how nectar foragers assess their colony's nutritional status. Behav. Ecol. Sociobiol. 24, 181-199. doi: 10.1007/BF00292101

Seeley, T. D. (2010). Honeybee Democracy. Princeton, NJ: Princeton University Press.

Seeley, T. D., and Visscher, P. K. (1988). Assessing the benefits of cooperation in honeybee foraging: search costs, forage quality, and competitive ability. Behav. Ecol. Sociobiol. 22, 229-237. doi: 10.1007/BF00299837

Sherman, G., and Visscher, P. K. (2002). Honeybee colonies achieve fitness through dancing. Nature 419, 920-922. doi: 10.1038/nature01127

Tan, K., Yang, M. X., Radloff, S. E., Hepburn, H. R., Zhang, Z. Y., Luo, L. J., et al. (2008). Dancing to different tunes: heterospecific deciphering of the honeybee waggle dance. Naturwissenschaften 95, 1165-1168. doi: 10.1007/s00114-0080437-1

Von Frisch, K. (1967). The Dance Language and Orientation of Bees. Cambridge, MA: Harvard University Press.

Wongsiri, S., Thapa, T., Oldroyd, B., and Burgett, D. (1996). A magic bee tree: home to Apis dorsata. Am. Bee J. 136, 796-799.

Zachos, J., Pagani, M., Sloan, L., Thomas, E., and Billups, K. (2001). Trends, rhythms, and aberrations in global climate $65 \mathrm{Ma}$ to present. Science 292, 686-693. doi: $10.1126 /$ science. 1059412

Conflict of Interest Statement: The authors declare that the research was conducted in the absence of any commercial or financial relationships that could be construed as a potential conflict of interest.

Copyright $\odot 2015$ I'Anson Price and Grüter. This is an open-access article distributed under the terms of the Creative Commons Attribution License (CC BY). The use, distribution or reproduction in other forums is permitted, provided the original author(s) or licensor are credited and that the original publication in this journal is cited, in accordance with accepted academic practice. No use, distribution or reproduction is permitted which does not comply with these terms. 